\title{
Phosphoglucose isomerase (EC 5.3.1.9) isozymes in diploid and tetraploid Polygala species: evidence for gene duplication and diversification
}

\author{
Andrew J. Lack and \\ Quentin O. N. Kay
}

Ecology and Evolution Research Group, School of Biological Sciences, University College, Swansea, SA2 8PP, U.K.

Phosphoglucose isomerase (PGI, EC 5.3.1.9) isozymes were examined by electrophoresis in the three common British species of Polygala, the diploids $\boldsymbol{P}$. serpyllifolia and $\boldsymbol{P}$. calcarea and the tetraploid $\boldsymbol{P}$. vulgaris. All three species share the most anodal band which is probably the form of the enzyme occurring in the plastids (PGI-1). Individuals of the two diploid species each have one further band, probably the cytosolic form of the enzyme (PGI-2), with two phenotypes in each species, one of which is common to both. Individuals of $P$. vulgaris have one, three or six PGI-2 bands and 10 different homozygous phenotypes were observed. The commonest phenotypes in most populations show three bands with a central heterodimeric band staining more intensely than the outer two bands. Although $P$. vulgaris is a predominantly self-fertilising species with no vegetative spread, many populations or sub-populations consist almost entirely of three-banded phenotypes. This indicates that the three-banded phenotypes are "fixed heterozygotes" resulting from the duplication of the Pgi-2 locus in the tetraploid. Heterozygotes between different three-banded forms show six bands in which the staining intensities are consistent with random pairing of the subunits. Plants showing silencing of one of the duplicate alleles were found in two small isolated areas in West Glamorgan. The biochemical diversity produced by the multiplicity of enzyme morphs in the tetraploid $P$. vulgaris may have contributed to its success. It is the most common, widespread and ecologically wide-ranging species in the genus in Europe.

\section{INTRODUCTION}

Phosphoglucose isomerase (PGI, EC 5.3.1.9), detected by electrophoresis, frequently shows polymorphic variation in plants. In previous studies of a range of animals and plants it has always been shown to be a dimeric enzyme, with heterozygotes showing three bands, and the central, heterodimeric band usually staining more intensely than the outer two homodimeric bands (Avise and Kitto, 1973; Gottlieb, 1977; 1981; Adams and Allard, 1977). PGI from Polygala species stains very clearly on starch gels and shows considerable variation between individuals. The enzyme shows a diversity of phenotypes in Polygala species, and shows the effects of gene duplication particularly clearly in the tetraploid $P$. vulgaris. Other enzyme systems also show evidence of duplication in this species.

Gene duplication can occur in plant evolution both via polyploidy (Ohno, 1970; Roose and Gottlieb, 1976; 1980; Gottlieb, 1981; Gottlieb and Higgins, 1984) and via repetitions in particular DNA sequences (Gottlieb, 1977; 1981). When such a duplication has occurred and the two loci behave independently, a plant homozygous for different alleles at the two loci will appear to be heterozygous, since the products of both alleles will appear, with any hybrid band, in the preparation. Such "fixed heterozygosity" has been demonstrated for PGI in the plant genera Clarkia (many diploid species; Gottlieb, 1977) and Festuca (hexaploid F. microstachys; Adams and Allard, 1977) and in many bony fishes (Avise and Kitto, 1973). It has been demonstrated for other enzyme systems in Triticum (Barber et al., 1968; Hart, 1969; Hart and Langston, 1977) Zea (Freeling and Schwartz, 1973), Stephanomeria (Gottlieb, 1973), Helianthus (Torres, 1974), Hordeum (Babbel and Wain, 1977) and Tragopogon (Roose and Gottlieb, 1976; 1980). In autopolyploids polysomic inheritance may occur with corresponding segregation among the four alleles in the offspring (Little, 1958; Grant, 1975).

If a pair of duplicated loci behave independently, their properties may diverge, with one of the loci changing and, possibly, acquiring a new function, while the other locus retains its original 
properties. This has been proposed as a particular stimulus for evolution in polyploids (Ohno, 1970; MacIntyre, 1976; Zuckerkandl, 1978).

In this paper we present evidence for duplication and divergence of Pgi loci among two diploid and one tetraploid species of Polygala (Polygalaceae).

\section{THE SPECIES}

Polygala vulgaris L., $P$. serpyllifolia Hose and $P$. calcarea $\mathrm{F}$. W. Schultz are closely related and very similar in appearance. In Britain $P$. vulgaris is a widespread species of basic to neutral grassland, particularly common in the south. $P$. serpyllifolia is widespread in acid habitats and is more frequent in the north and west. The two species overlap considerably in range (Perring and Walters, 1976) although they are separated by habitat in most localities. $P$. calcarea is confined to chalk and limestone in southern England, where it is locally common and very frequently occurs with $P$. vulgaris. A fourth species, $P$. amarella L., has a very restricted distribution in Britain and was not included in this study. Glendinning (1960) and Moore (1982) reported a diploid number of $2 n=34$ for British populations of $P$. serpyllifolia and $P$. calcarea. Trueman (1973), in a critical study of the genus in Britain, recorded $2 n=32$ in $P$. serpyllifolia and $2 n=34$ in $P$. calcarea. The tetraploid number of $2 n=68$ has been found in British populations of P. vulgaris (Glendinning, 1960; Trueman, 1973; Moore, 1982). The chromosomes of Polygala species are very small and poorly discernible and the meiotic configurations have not been analysed. Lower chromosome numbers were reported by earlier workers for $P$. vulgaris from other parts of Europe, but Glendinning (1960) considered that these are likely to. have been errors. Tetraploid $P$. serpyllifolia has been reported from some parts of Europe (Glendinning, 1960), but the relationship between these forms and British $P$. serpyllifolia is not clear. Hybridisation between $P$. calcarea and $P$. vulgaris may be quite frequent where the two species occur together but the triploid hybrids have very low fertility (Trueman, 1973). Hybridisation between $P$. vulgaris and $P$. serpyllifolia has never been recorded (Trueman, 1973).

\section{METHODS}

Plants of each species were sampled from a number of populations (fig. 1, table 1). Within each population, samples were collected to cover the range of visible morphological variation and the geographical extent of the population or sub-population, with a minimum sampling distance of $25 \mathrm{~cm}$. Individuals do not spread vegetatively further than about $5 \mathrm{~cm}$ and each sample was collected from a different plant.

Enzymes were assayed using horizontal starch gel electrophoresis in Shandon U77 Kohn tanks. The electrophoresis procedure was similar to that described by Shields, Orton and Stuber (1983) and the most satisfactory buffer for PGI was found to be $0.5 \mathrm{M}$ Tris, $0.24 \mathrm{M}$ Boric acid, 0.016 M EDTA with a one-tenth dilution for the gel. Staining was carried out using recipes following Shaw and Prasad (1970). One to three leaves of each sample plant were ground in water or $0.1 \mathrm{M}$ Tris $\mathrm{HCl}$ buffer at $\mathrm{pH} 7.5$ and the crude extract was absorbed on thin Whatman No. 3 filter paper wicks $(6 \times$ $3 \mathrm{~mm}$ ).

Self-pollination occurs automatically in all three species. Crosses between plants of different homozygous genotypes were made by removing the undehisced anthers from unopened buds before cross-pollination. Progeny analyses were made using seed taken from capsules formed by automatic self-pollination on isolated plants.

\section{RESULTS}

\section{Differences between species}

Fig. 2 shows all PGI phenotypes observed to date and table 1 lists the numbers of plants of each phenotype found in each locality. The banding patterns of several phenotypes of Polygala vulgaris are shown in fig. 3. In all plants of all three species the most anodal PGI band (PGI-1) is universal and invariant in its position, but it usually develops more slowly than other PGI bands. $P$. serpyllifolia and $P$. calcarea each show one other PGI band with two alternative positions in each species, presumably representing different phenotypes of another PGI locus (Pgi-2). One of these phenotypes is the same in both species. In P. serpyllifolia, phenotype 1 (fig. 2) has so far only been found in populations in West Glamorgan, but sample sizes from other areas are fairly small (table 1). In $P$. calcarea both phenotypes have been recorded in all populations examined (from Kent, Dorset and Wiltshire).

Individual plants of $P$. vulgaris have one, three, five or six PGI bands, in addition to PGI-1. In nearly all plants of $P$. vulgaris that have been examined, one of these bands has the same elec- 


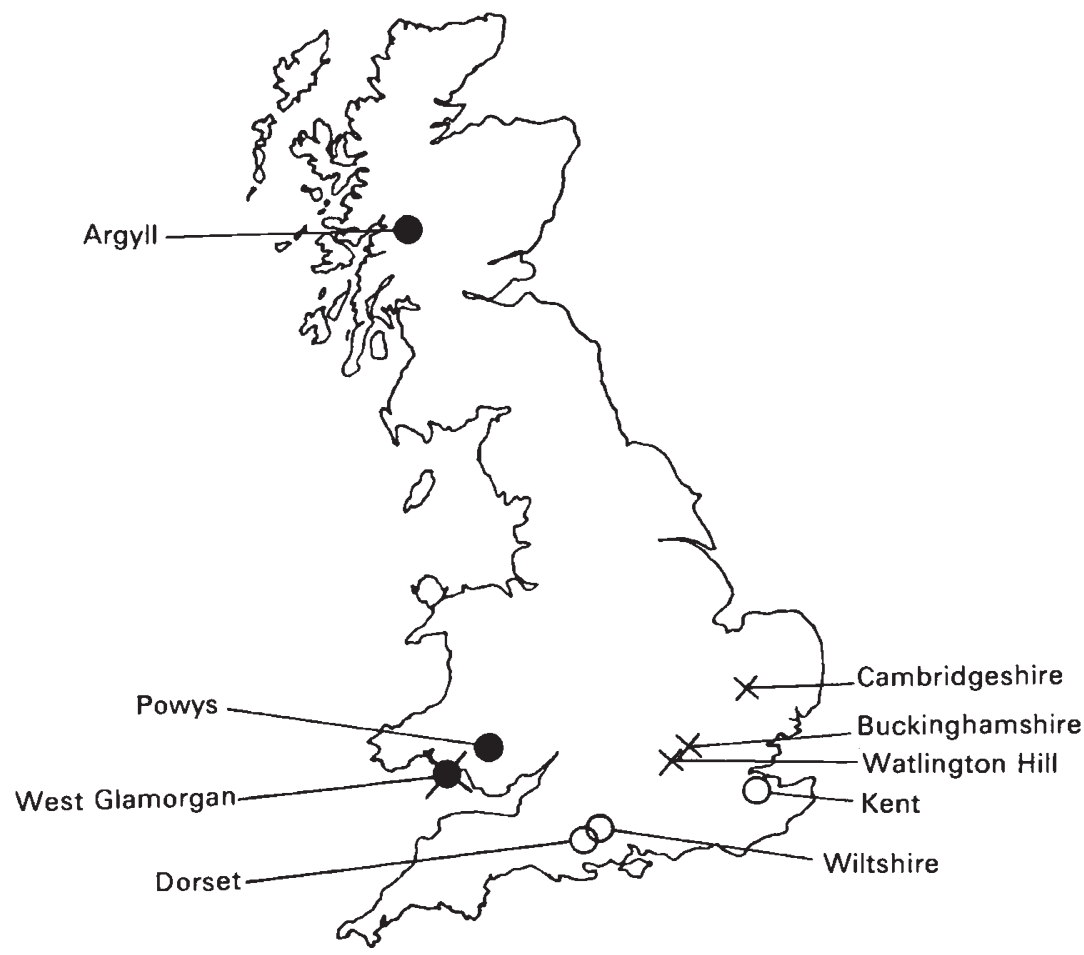

Figure 1 Locations of population samples. $=$ Polygala serpyllifolia, $O=P$. calcarea, $\times=P$. vulgaris.

trophoretic mobility as the common PGI-2 phenotype which occurs in both $P$. serpyllifolia and $P$. calcarea (fig. 2), and all these bands have been designated as PGI-2, for reasons given later. Twenty different PGI-2 phenotypes have been observed in $P$. vulgaris.

$P$. vulgaris plants with three PGI-2 bands are very frequently observed (table 1); in the West Glamorgan populations that were studied $90 \cdot 2$ per cent of the sampled plants were three-banded and only 2.8 per cent were single-banded. In the threebanded plants the central band is always mid-way between the faster and slower bands and is nearly always more intensely staining, the iypical pattern

Table 1 Numbers of plants of each PGI phenotype sampled from each field population

\begin{tabular}{|c|c|c|c|c|c|c|c|c|c|c|c|c|c|c|c|c|c|c|c|c|}
\hline \multirow{2}{*}{$\frac{\text { Locality }}{P . \text { serpyllifolia }}$} & \multicolumn{20}{|c|}{ Phenotype } \\
\hline & 1 & 2 & & & & & & & & & & & & & & & & & & \\
\hline West Glamorgan & 10 & 45 & & & & & & & & & & & & & & & & & & \\
\hline Powys & & 11 & & & & & & & & & & & & & & & & & & \\
\hline Argyll & & 15 & & & & & & & & & & & & & & & & & & \\
\hline P. calcarea & 1 & 2 & & & & & & & & & & & & & & & & & & \\
\hline $\begin{array}{l}\text { combined } \\
P . \text { vulgaris }\end{array}$ & 13 & 37 & & & & & & 8 & 9 & 10 & 11 & 12 & 13 & 14 & 15 & 16 & 17 & 18 & 19 & 20 \\
\hline $\begin{array}{l}\text { P. vulgaris } \\
\text { Limestone cliffs }\end{array}$ & $\begin{array}{r}1 \\
32\end{array}$ & $\begin{array}{r}2 \\
16\end{array}$ & $\begin{array}{r}3 \\
36\end{array}$ & 4 & 5 & 6 & 7 & 8 & 4 & & & 10 & 5 & & & & & & & \\
\hline West Glamorgan & & & & & & & & & & & & & & & & & & & & \\
\hline $\begin{array}{l}\text { Oxwich sand dunes } \\
\text { West Glamorgan }\end{array}$ & 73 & & 28 & & & & & & & & & 3 & & & & & & & & \\
\hline $\begin{array}{l}\text { Whiteford sand dunes } \\
\text { West Glamorgan }\end{array}$ & 44 & & & & & & & & & 3 & & & & & & & & & & \\
\hline $\begin{array}{l}\text { Chalk grassland } \\
\text { Buckinghamshire }\end{array}$ & 18 & 5 & & 39 & & & & & & & 2 & & & & & 4 & 4 & & & \\
\hline $\begin{array}{l}\text { Chalk grassland } \\
\text { Watlington Hill, Oxon. }\end{array}$ & 5 & & & 60 & 5 & 20 & 2 & 2 & & & & & & 3 & 1 & & & 1 & 5 & 3 \\
\hline $\begin{array}{l}\text { Watlington Hill, Oxon. } \\
\text { Chalk grassland } \\
\text { Cambridgeshire }\end{array}$ & 13 & 3 & & 36 & & & & & & & 3 & & & & & 4 & & & & \\
\hline
\end{tabular}




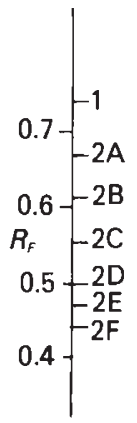

suggested genotype
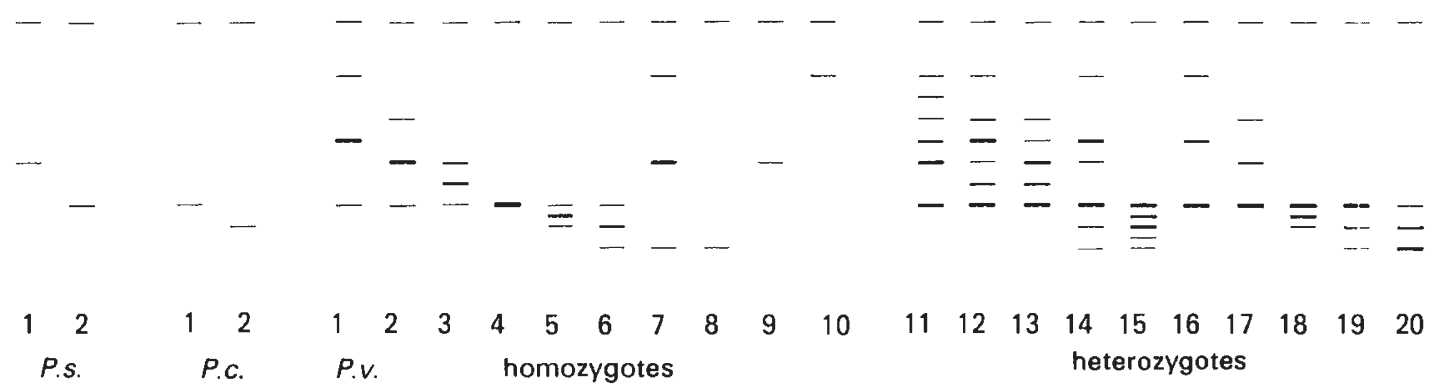

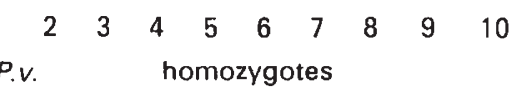

11

1213

$\begin{array}{ll}14 & 15 \\ \text { heter } & \\ \text { A } & D \\ D & D \\ D & E \\ \text { F } & F\end{array}$

$\begin{array}{llllllllll}A & B & C & D & D & D & A & F & C & A \\ A & B & C & D & D & D & A & F & C & A \\ D & D & D & D & E & F & F & n & n & n \\ D & D & D & D & E & F & F & n & n & n\end{array}$

$\begin{array}{llllllllll}A & A & B & A & D & A & B & D & D & D \\ B & C & C & D & D & D & D & D & D & F \\ D & D & D & D & E & D & D & D & D & F \\ D & D & D & F & F & D & D & E & F & F\end{array}$

Figure 2 Diagrammatic representation of PGI phenotypes observed in Polygala serpyllifolia (P.s.), P. calcarea (P.c.) and P. vulgaris (P.v.) in Britain. $R_{F}$ is the migration distance of the bands proportional to the distance covered by the marker front.

for heterozygotes of a dimeric enzyme with random pairing of the subunits. Results from progeny analyses are shown in table 2 . Individuals of phenotypes 1 and 3, both showing a three-banded pattern, produced progeny entirely of the parental phenotype when self-pollinated. The heterozygosity shown by these plants is "fixed" and it seems clear that the Pgi-2 locus has been duplicated and that the two resulting loci behave independently. Since fixed heterozygosity has been found only in the tetraploid $P$. vulgaris, the duplication has probably arisen as a result of chromosome doubling, but it is not clear whether auto- or allotetraploidy

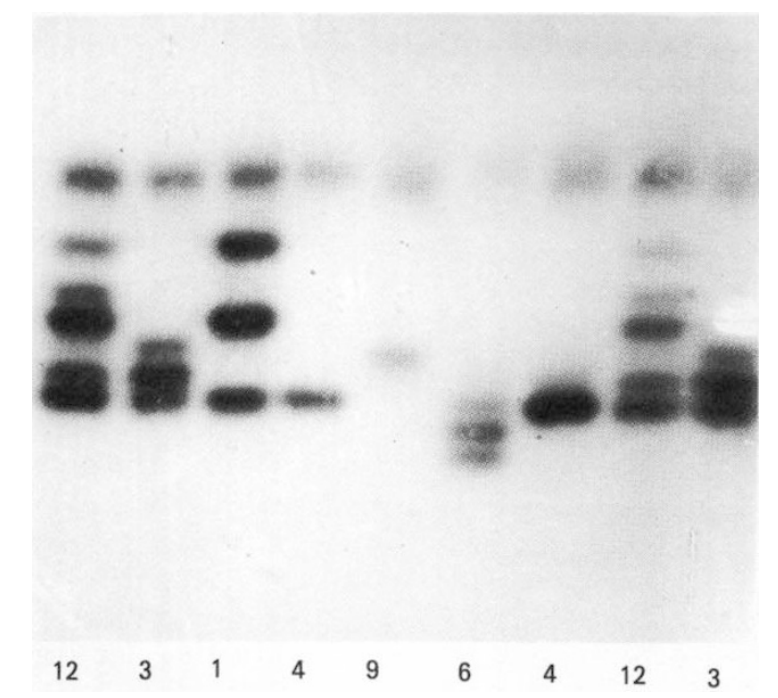

Figure 3 Electrophoretic phenotypes of PGI from selected individuals of Polygala vulgaris. is involved. The two loci must be closely similar at the genetic level since the subunits associate more or less at random. Although the two loci appear to be clearly differentiated in some populations, with one always producing the $\mathrm{D}$ band and the other being variable, in other populations, particularly Watlington Hill, it is not clear which locus produces a particular enzyme band. For this reason we have designated all four alleles as Pgi-2, despite the clear evidence for two separate loci.

$F_{1}$ individuals originating from crosses between phenotype 1 and phenotype 3 showed phenotype 12 , with six PGI-2 bands. Progeny from individuals of phenotype 12 produced offspring of phenotypes 1,3 and 12 segregating in the typical disomic $1: 1: 2$ ratio (table 2 ). Phenotype 12 is clearly heterozygous at one locus, because it shows each of the bands of the two parents with an additional heterodimeric band between the upper bands of the parents, making six bands in all.

These observations make it possible to postulate genotypes for all the banding patterns observed in $P$. vulgaris. The alleles can be designated by the letters $A$ to $F, A$ corresponding to the

Table 2 PGI phenotypes of progeny grown from seed set by untouched flowers on plants of Polygala vulgaris of known PGI phenotype

\begin{tabular}{lccc}
\hline & \multicolumn{3}{c}{ Progeny phenotype } \\
\cline { 2 - 4 } Parent phenotype & 1 & 3 & 12 \\
\hline 1 & 56 & 13 & \\
3 & 6 & 9 & 15 \\
12 & & & \\
\hline
\end{tabular}


most anodal (homodimeric) band (fig. 2). Phenotype 1 can then be referred to the Pgi-2 genotype AADD, phenotype 2 to Pgi-2 BBDD, phenotype 3 to Pgi-2 CCDD, phenotype 5 to Pgi-2 DDEE, and phenotype 6 to Pgi-2 DDFF (fig. 2). In each phenotype the central heterodimeric band stains approximately twice as intensely as the homodimeric bands, consistent with random pairing of the subunits (fig. 3). Phenotype 4 has a single heavily staining PGI-2 D band strongly suggesting that its genotype is Pgi-2 DDDD, with both loci homozygous for the D allele. Pgi-2 D is found in 636 out of the total of 647 plants of $P$. vulgaris that we have examined and it is shared with both diploid species, suggesting that it may be ancestral. Of the five and six-banded phenotypes, phenotype 12 can be referred to the single-locus heterozygous genotype Pgi-2 ACDD. With random pairing of the subunits the dimers will occur in the proportions (from the most anodal band) 1AA: 2AC: 4AD: 1CC: 4CD: 4DD. This corresponds almost exactly to the staining intensities visible on the gels (figs. 2 and 3). The CC band, which lies between the intensely staining $A D$ and $C D$ bands, is always relatively faint. It has not yet been possible to carry out progeny analyses for the other six-banded phenotypes, but the relative staining intensities of the bands and co-occurrence with the presumed parents strongly suggest that phenotypes 11,13 , 14 and 15 are also single-locus heterozygotes, with Pgi-2 genotypes ABDD, BCDD, AFDD, EFDD respectively. The presumed parents have the phenotypes 1 and 2, 2 and 3,1 and 6,5 and 6 . Phenotypes 13 and 15 show only five bands because two of the six dimers in each phenotype have identical mobilities. Phenotypes 16, 17, 18 and 19 have three bands with mobilities identical to those of phenotypes 1, 2, 5 and 6 respectively, but with the PGI-2 D band staining much more intensely. This suggests that they are heterozygotes, with the Pgi-2 genotypes ADDD, BDDD, EDDD and FDDD respectively, originating from a cross between the corresponding homozygous threebanded phenotype and phenotype 4 . Phenotype 20 appears to be another heterozygote with the genotype DFFF, perhaps originating from a cross between phenotype 6 and the rare single-banded phenotype 8 . These three-banded heterozygote morphs are rare and it has not yet been possible to carry out experimental crosses and progeny analyses to confirm their probable genotypes. Given random pairing, phenotype 16 should produce enzyme dimers in the proportions $1 \mathrm{AA}: 6 \mathrm{AD}$ : 9DD, and similarly for other three-banded heterozygotes. Though the AA band (or equivalent) is sometimes a little darker than this might suggest, these proportions are reflected in staining intensities on the gels. All the confirmed and possible heterozygotes were growing in small numbers near their putative parents.

Two single-banded phenotypes, 9 and 10, have been found only as isolated groups of plants, each in a single population; phenotype 9 at one spot in grassy limestone heathland on the sea-cliffs of West Glamorgan, growing with phenotypes 1 and 3, phenotype 10 in a small area of calcareous sanddune grassland at Whiteford, West Glamorgan, growing with phenotype 1 . Apart from these rare single-banded plants, which lack the PGI-2 D band, all plants in these and nearby populations are three-banded, or six-banded heterozygotes, with the $\mathrm{D}$ band as one of these. Phenotypes 9 and 10 may be homozygous at one locus for nonfunctional or "null" alleles in place of Pgi-2 D. The null allele may have arisen initially as a mutation in heterozygous form and become homozygous through self-pollination. These phenotypes would then have Pgi-2 genotypes CCnn (phenotype 9) and AAnn (phenotype 10), where $\mathrm{n}$ is a null allele. This would lead to a staining intensity very similar to that of the $A$ band of normal, three-banded "fixed heterozygotes". Alternatively, these phenotypes could have arisen by mutation at the Pgi-2 D locus to the same morph as was present at the other locus (different in the two areas) or through quadrivalent formation at meiosis, leading to gametes with the same allele at both loci. Stabilisation in either case could follow through self-fertilisation. If quadrivalents were formed one would expect plants with a single PGI-2 D band to be found in the same area, but these were not found in either area. Since there is no other evidence for tetrasomic inheritance, origin of the rare single-banded phenotypes by this mechanism seems very unlikely. Furthermore, genotypes AAAA and CCCC would be expected to show a single intensely staining band. The faintness of the bands suggests that null alleles have been formed. Phenotypes 9 and 10 are both extremely restricted in distribution, but there appeared to be no loss of vigour in the plants. Indeed one of the phenotype 9 plants was among the largest plants in its immediate vicinity. The single-banded phenotype 8 may have arisen in the same way and may also have a null allele. The population at Watlington Hill, where it occurs, is extremely variable and contains several phenotypes found nowhere else. This population requires further investigation before definite conclusions can be made. 


\section{Dfferences between populations of $\mathrm{P}$. vulgaris}

Tables 1 and 3 show that there are clear differences between the populations studied. Gene frequencies (table 3) have been calculated for both Pgi-2 loci together, so a frequency of 0.5 would be recorded for an allele present in all plants as a homozygote at one locus, but not occurring at the other locus (e.g., allele $\mathrm{D}$ at Oxwich). Allele $\mathrm{D}$, present in all plants except a few rare and isolated plants, accounts for over 75 per cent of the alleles in the English populations where it is frequently present at both loci, as the single-banded phenotype 4 (with the genotype DDDD). This phenotype has not been found in the Welsh populations. Here allele D occurs as a homozygote at one locus in nearly all plants, but other alleles are present at the other Pgi-2 locus. Allele A, present in all populations so far examined, is particularly frequent in both sand dune populations, at Whiteford occurring in all plants. Allele B appears to be of infrequent occurrence in three widely separated populations and allele $\mathrm{C}$ is confined to the Welsh populations. The large population at Watlington Hill appears to have two alleles not found anywhere else, allele $F$ at a fairly high frequency. This leads to a wide range of phenotypes being expressed in this one population.

\section{DISCUSSION}

The most anodal PGI band, PGI-1, may be the form of the enzyme that is localised in the plastids. Distinct plastid (PGI-1) and cytosolic (PGI-2) forms of PGI, coded for at different loci, have been shown to exist in several species of angiosperm
(Schnarrenberger and Oeser, 1974; Schnarrenberger et al., 1975; Gottlieb and Weeden, 1979; 1981; Weeden and Gottlieb, 1979; 1982; Jones, 1984). The most anodal PGI band was the same in all three species of Polygala, a lack of diversity typical of plastid isozymes (Gottlieb and Weeden, 1981). The remaining PGI bands (PGI-2) were polymorphic, and were, presumably, the cytosolic isozymes. The two diploid species showed only two morphs each, with no heterozygotes yet detected (all species appear to show a high level of selfpollination), but $P$. vulgaris showed 10 different homozygotes and 10 of the possible single-locus heterozygotes. The sample sizes for the diploid species were smaller, but the plants came from a wide geographical range, and it appears that there is much less variation in these species. This type of diversity is typical of polyploids. It has been suggested that polyploids may gain biochemical diversity as a consequence of gene duplication (Barber, 1970; Johnson, 1974) which allows them to be more flexible and tolerant in their ecological requirements. Zangerl and Bazzaz (1984) reported that different PGI genotypes of Amaranthus retroflexus differed in their ecological distribution. The potentially greater range of tolerance and flexibility of the polyploid Polygala vulgaris, compared with the diploid species in the genus, is supported by its known ecological and geographical range in Europe. P. vulgaris is the most widely distributed European species of Polygala (McNeill, 1968) and is the commonest species in many parts of northern Europe. It is very variable (McNeill, 1968), and has been classified as several different infraspecific taxa or even species in the past, though it is clear that they form part of a continuous range of phenotypic variation within $P$. vulgaris (Trueman,

Table 3 Frequencies of Pgi-2 alleles in natural populations of Polygala vulgaris

\begin{tabular}{|c|c|c|c|c|c|c|c|c|}
\hline \multirow[b]{2}{*}{ Population } & \multirow{2}{*}{$\begin{array}{l}\text { No. of } \\
\text { plants } \\
\text { sampled }\end{array}$} & \multicolumn{7}{|c|}{$P g i-2$ allele } \\
\hline & & A & B & $\mathrm{C}$ & D & $\mathrm{E}$ & $\mathrm{F}$ & $\mathrm{n}^{*}$ \\
\hline $\begin{array}{l}\text { Limestone cliffs } \\
\text { West Glamorgan }\end{array}$ & 103 & $0 \cdot 18$ & 0.09 & $0 \cdot 23$ & 0.48 & & & 0.02 \\
\hline $\begin{array}{l}\text { Oxwich sand dunes } \\
\text { West Glamorgan }\end{array}$ & 104 & $0 \cdot 36$ & & $0 \cdot 14$ & $0 \cdot 50$ & & & \\
\hline $\begin{array}{l}\text { Whiteford sand dunes } \\
\text { West Glamorgan }\end{array}$ & 47 & $0 \cdot 50$ & & & 0.47 & & & 0.03 \\
\hline $\begin{array}{l}\text { Chalk grassland } \\
\text { Buckinghamshire }\end{array}$ & 72 & $0 \cdot 15$ & 0.06 & & $0 \cdot 80$ & & & \\
\hline $\begin{array}{l}\text { Chalk grassland } \\
\text { Watlington Hill, Oxon. }\end{array}$ & 107 & 0.04 & & & 0.77 & 0.03 & $0 \cdot 15$ & $(0.01 ?)$ \\
\hline $\begin{array}{l}\text { Chalk grassland } \\
\text { Cambridgeshire }\end{array}$ & 59 & 0.14 & $0 \cdot 04$ & & 0.82 & & & \\
\hline
\end{tabular}

* see text for possible alternative 
1973). It is one of only two European species of Polygala in which polyploidy has been reported, and the only one in which polyploids are known to be widespread (McNeill, 1968; Trueman, 1973). Its ecological range and distribution within the British Isles are wider than those of either diploid species in this study.

Phenotype 4 (PGI-2 DDDD) may be the ancestral type in $P$. vulgaris, since a form of this mobility, homozygous at both loci, is shown by both diploid species and is present in nearly all plants. Its great frequency as the sole allele in many plants in the eastern populations (those nearer the centre of distribution of the species) also suggests that it may be ancestral. There are fairly large differences between populations in the different parts of the country suggesting that there may have been little contact between them. We have found that $P$. vulgaris is largely self-pollinated, and this is reffected by the low frequency of heterozygotes (other than "fixed heterozygotes") found in all populations. Seed dispersal is extremely limited. The seeds are heavy and have no adaptations for mechanical dispersal, though we have observed ants gathering them and moving them up to $2 \mathrm{~m}$. The extreme diversity in PGI in the population at Watlington may have arisen from past hybridisation and introgression from $P$. calcarea. Trueman (1973) examined this population and suggested that, although there was no evidence of pure $P$. calcarea and the population in the main resembled $P$. vulgaris, it had several morphological characters found in $P$. calcarea. PGI alleles $\mathrm{E}$ and $\mathrm{F}$ were found only in this population of $P$. vulgaris, and $E$ has the same mobility as one allele found in all $P$. calcarea populations. This adds strength to the suggestion that this population may, at some time in the past, have incorporated genes from $P$. calcarea, but further evidence would be desirable. Hybridisation between the two species was recorded by Trueman (1973) in most places where the two species occur together, but the presumed hybrids are normally triploid and have very low fertility (Trueman, 1973).

The occurrence of "null", non-functional alleles has been reported in a few polyploid species, particularly in fishes (Ferris and Whitt, 1979; Stoneking et al., 1981). Among plants it has very rarely been reported but has been demonstrated for PGI in Clarkia (Gottlieb, 1977) and Festuca (Adams and Allard, 1977). Allendorf (1979) and Li (1980) have suggested that such "gene silencing" could arise frequently and spread in organisms with duplicate loci. In Polygala vulgaris the occurrence in two very small isolated areas (and possibly a third) of a few plants probably showing a null $\mathrm{Pgi}-2$ allele suggests that gene silencing is not common and has not spread. In both places it has given rise to plants with a single enzyme form while all nearby plants show three forms.

Acknowledgements We are very grateful to Betty Griffiths for help with laboratory work and to Catherine Fisher, Martin Ford, David Skibinski and David Stevens for useful discussion, advice, and critical comments on the manuscript. The study was supported by a research grant from the Natural Environment Research Council.

\section{REFERENCES}

ADAMS, W. T. AND ALLARD, R. W. 1977. Effect of polyploidy on phosphoglucose isomerase diversity in Festuca macra stachys. Proc. Nat. Acad. Sci., USA., 74, 1652-1656.

ALLENDORF, F. W. 1979. Rapid loss of duplicate gene expression by natural selection. Heredity, 43, 247-258.

AVISE, J. C. AND KITTO, G. B. 1973. Phosphoglucose isomerase gene duplication in the bony fishes: an evolutionary history. Biochem. Genet., 8, 113-132.

BABBEL, G. R. AND WAIN, R. P. 1977. Genetic structure of Hordeum jubatum 1. Outcrossing rates and heterozygosity levels. Can. J. Genet. Cytol., 19, 143-152.

BARBER, H. N. 1970. Hybridization and the evolution of plants. Taxon, 19, 154-160.

BARBER, H. N., DRISCOLL, C. J., LONG, P. M. AND VICKERY, R. S. 1968. Protein genetics of wheat and homoeologous relationships of chromosomes. Nature, 218, 450-452.

FERRIS, S. D. AND WHITT, G. S. 1979. Evolution of the differential regulation of duplicate genes after polyploidization. J. Mol. Evol., 12, 267-317.

FREELING, M. AND SCHWARTZ, D. 1973. Genetic relationships between the multiple alcohol dehydrogenases of maize. Biochem. Genet., 8, 27-36.

Glendinning, D. R. 1960. Cytology of Polygala. Nature, 188, 604-605.

GOTTLiEB, L. D. 1973. Genetic control of glutamate oxaloacetate transaminase isozymes in the diploid plant Stephanomeria exigua and its allotetraploid derivatives. Biochem. Genet., 9, 97-107.

GOTTLIEB, L. D. 1977. Evidence for duplication and divergence of the structural gene for phosphoglucoisomerase in diploid species of Clarkia. Genetics, 86, 289-307.

GOTTLIEB, L. D. 1981. Electrophoretic evidence and plant populations. Progress in Phytochemistry, 7, 1-46.

GotTlieB, L. D. 1982. Conservation and duplication of isozymes in plants. Science, 216, 373-380.

GotTlieb, L. D. AND HigGins, R. C. 1984. Evidence from subunit molecular weight suggests that hybridization was the source of the phosphoglucose isomerase gene duplication in Clarkia. Theor. Appl. Genet., 68, 369-374.

GotTlieB, L. D. AND WEEDEN, N. F. 1979. Gene duplication and phylogeny in Clarkia. Evolution, 33, 1024-1039.

GoTTLIEB, L. D. AND WEEDEN, N. F. 1981. Correlation between subcellular location and phosphoglucose isomerase variability. Evolution, 35, 1019-1022.

GRANT, V. 1975. Genetics of Flowering Plants, Columbia University Press, New York and London. 
HART, G. E. 1969. Genetic control of alcohol dehydrogenase isozymes in Triticum dicoccum. Biochem. Genet., 3, 617-625.

HART, G. E. AND LANGSTON P. J. 1977. Chromosomal location and evolution of isozyme structural genes in hexaploid wheat. Heredity, 39, 263-277.

JOHNSON, G. B. 1974. Enzyme polymorphism and metabolism. Science, 184, 28-37.

JONES, T. W. A. 1984. Development of phosphoglucose isomerase (EC 5.3.1.9) isozymes in perennial ryegrass (Lolium perenne). Physiologia Plantarum, 60, 203-207.

LI, W-H. 1980. Rate of gene silencing at duplicate loci: a theoretical study and interpretation of data from tetraploid fishes. Genetics, 95, 237-258.

LITTLE, T. M. 1958. Gene segregation in autotetraploids II. Bot. Rev., 24, 318-339.

MACINTYRE, R. J. 1976. Evolution and ecological value of duplicate genes. Ann. Rev. Ecol. Syst., 7, 421-468.

MCNeIll, J. 1968. Polygala. In Tutin, T. G. et al. (ed). Flora Europaea Vol. 2, Cambridge University Press, Cambridge.

MoORE, D. M. 1982. Flora Europaea Check-List and Chromo some Index, Cambridge University Press, Cambridge.

OHNO, S. 1970. Evolution by Gene Duplication, Springer-Verlag, New York.

PERRING, F. H. AND WALTERS, S. M. 1976. Atlas of the British Flora, 2nd ed., EP publishers, Wakefield.

Roose, M. L. AND GotTlieB, L. D. 1976. Genetic and biochemical consequences of polyploidy in Tragopogon. Evolution, 30, 818-830.

ROOSE, M. L. AND GOTTLIEB, L. D. 1980. Biochemical properties and level of expression of alcohol dehydrogenase in the allotetraploid plant Tragopogon miscellus and its diploid progenitors. Biochem. Genet., 18, 1065-1085.

SCHNARRENBERGER, C. AND OESER, A. 1974. Two isoenzymes of glucose phosphate isomerase from spinach leaves and their intracellular compartmentation. Eur. J. Biochem., $45,77-82$,

SCHNARRENBERGER, C., TETOUR, M. AND HERBERT, M. 1975. Development and intracellular distribution of enzymes of the oxidative pentose phosphate cycle in radish cotyledons. Plant Physiology, 56, 836-840.
SHAW, C. R. AND PRASAD, R. 1970. Starch gel electrophoresis of enzymes-a compilation of recipes. Biochem. Genet., 4, 297-320.

SHIELDS, C. R., ORTON, T. J. AND STUBER, C. W. 1983. An outline of general resource needs and procedures for the electrophoretic separation of active enzymes from plant tissue. In Tanksley, S. D. and Orton, T. J. (ed) Isozymes in Plant Genetics and Breeding, Part A, Elsevier, Amsterdam, pp. 443-468.

STONEKING, M., MAY, B. AND WRIGHT, J. E. 1981. Loss of duplicate gene expression in salmonids: evidence for a null allele polymorphism at the duplicate aspartate aminotransferase loci in brook trout (Salvelinus fontinalis). Biochem. Genet., 19, 1063-1077.

TORRES, A. M. 1974. An intergenic alcohol dehydrogenase isozyme in sunflowers. Biochem. Genet., 11, 301-308.

TRUEMAN, I. C. 1973. An Investigation of Variation in British Populations of Polygala L. Ph.D. thesis, University of Liverpool.

WEEDEN, N. F. 1983. Evolution of plant isozymes. In Tanksley, S. D. and Orton, T. J. (ed). Isozymes in Plant Genetics and Breeding, Part A, Elsevier, Amsterdam. pp. 139-156.

WEEDEN, N. F. AND GOTTLIEB, L. D. 1979. Distinguishing allozymes and isozymes of phosphoglucoisomerases by electrophoretic comparisons of pollen and somatic tissues. Biochem. Genet., 17, 287-296.

WEEDEN, N. F. AND GOTTlieB, L. D. 1982. Dissociation, reassociation and purification of plastid and cytosolic phosphoglucose isomerase isozymes. Plant Physiology, 69, 717-723.

ZANGERL, A. R. AND BAZZAZ, F. A. 1984. Niche partitioning between two phosphoglucoisomerase genotypes in Amaranthus retroflexus. Ecology, 65, 218-222.

ZUCKERKANDL, E. 1978. Multilocus enzymes, gene regulation and genetic sufficiency, J. Mol. Evol., 12, 57-89. 